\title{
Temporal changes in lipid condition and parasitic infection by digenean metacercariae of young-of-year common sole Solea solea (L.) in an Atlantic nursery ground (Bay of Biscay, France)
}

\author{
Eric D.H. Durieux ${ }^{\mathrm{a},{ }^{*}}$, Robert Galois ${ }^{\mathrm{a}}$, Marie-Laure Bégout ${ }^{\mathrm{a}}$, Pierre Sasal ${ }^{\mathrm{b}}$ and Françoise \\ Lagardère $^{a}$
}

\footnotetext{
a Centre de Recherche sur les Ecosystèmes Littoraux Anthropisés, CRELA UMR 6217 CNRS-IFREMERUniversité de La Rochelle, Place du Séminaire, BP5, 17137 L'Houmeau, France

${ }^{\mathrm{b}}$ Laboratoire de Parasitologie Fonctionnelle et Evolutive UMR 5555 CNRS-UPVD, Université de Perpignan Via Domitia, 52 Avenue Paul Alduy, 66860 Perpignan, France
}

*: Corresponding author : Eric.Durieux@ifremer.fr

\begin{abstract}
:
Little attention has been paid to flatfish parasitism as a potential factor of variation in year-class strength. The aim of this study was to evaluate the relationship between parasitic infection and nutritional condition of young-of-year (YOY) common sole. Sole were collected monthly from May (early settlement) to November 2004 in a mussel pole culture area, using a push-net or a trawl, and dissected for parasite identification and counts. Total lipids were extracted from the whole body and lipid classes quantified. Triacylglycerols to sterols (free form) ratio (TAG/ST) was used as an index of nutritional status. Digenean metacercariae infection, characterized by two dominant genera, displayed clear seasonal dynamics and the highest records yet reported for sole. Prevalence (P\%) and mean abundance (Ab $\pm \mathrm{SE})$ increased for Timoniella spp. (Acanthostomidae) from May ( $\mathrm{P} \%=22 \%$; $\mathrm{Ab}=1.9 \pm 1.1$ ) to August ( $\mathrm{P} \%=100 \% ; \mathrm{Ab}=51.2 \pm 10.4)$, and for Prosorhynchus spp. (Bucephalidae) from June ( $P \%=8 \% ; A b=0.1 \pm 0.0)$ to August $(P \%=100 \% ; A b=19.5 \pm 1.7)$. Epidemiological values reached a plateau after August. In this shellfish-dominated nursery area, YOY sole accumulated metacercariae in the presence of the first intermediate hosts which live in the same habitat. Total lipids decreased significantly from May to June and then remained constant until autumn, indicating a change in the proximate composition of YOY during this high growth period. Mean ( \pm SD) TAG/ST ratio increased from very low values in May-July ( 0.10 on average) to a peak in September $(0.57 \pm 0.31)$ and then fell back to values as low as before. YOY sole only stored energy as TAG prior to autumn. No relationship was found between YOY parasitic infection levels and lipid condition indices. However, the poor nutritional status and heavy infection level observed in November could dramatically lower over-winter survival of the YOY remaining in this shallow part of the nursery.
\end{abstract}

Keywords: Sole; YOY; Lipid condition; Parasitism; Metacercariae; Nursery 


\section{Introduction}

Coastal areas, such as estuaries and shallow water bays, serve as nurseries for juveniles of many marine fish species and especially flatfishes. Juveniles generally find good conditions for growth and survival in these essential habitats, due to abundant food, low predation risks and higher temperatures compared with offshore areas (Gibson, 1994). Nevertheless, nursery grounds are subject to highly variable environmental and anthropogenic factors (Yamashita et al., 2001). Conditions encountered by juveniles in coastal nurseries are therefore thought to greatly influence their growth and survival, via physiological mechanisms, and thus influence recruitment in the adult population (Gibson, 1994; van der Veer et al., 1994; Yamashita et al., 2001). Fundamental factors - such as temperature, oxygen, salinity, food availability, density, predation, river plume extension and pollutants - are known to affect growth, condition and survival, and are therefore taken into account when estimating nursery quality (Gibson, 1994; van der Veer et al., 1994; Nash and Geffen, 2000; van der Veer et al., 2001; Yamashita et al., 2001; Le Pape et al., 2003a).

Parasites have been shown to be able to regulate host populations (Anderson and May, 1978; May and Anderson, 1978). They can affect both physiology and ecology of their hosts (growth, condition, survival, fecundity, behavior) and thus their fitness (Combes, 2001). However, despite the importance of parasitism in ecology, this factor is rarely taken into account in fish ecology and even less in flatfish ecology. Like other small fishes though, young flatfishes are subjected to parasitism in nursery grounds, especially from digenean trematodes for which they can act as second intermediate hosts. Digeneans have a complex life cycle, which follows in marine environment the general scheme of having molluscs as first intermediate hosts, small fishes as second intermediate hosts and piscivorous fishes as definitive hosts (Cribb et al., 2001). Cercariae actively penetrate through the skin of their second intermediate host and encyst as metacercariae in the body. Transmission to the 
definitive host then occurs through predation. Metacercariae, like all parasitic stages, are metabolically dependent on their host and use some of their host's energy for their own development and maintenance. Although studies on the effects of digenean metacercariae on fish are scarce, some have shown a clear negative impact of these parasites on growth, condition and survival of freshwater fishes (Lemly and Esch, 1984; Coleman and Travis, 1998; Johnson and Dick, 2001; Collyer and Stockwell, 2004). Parasitism is thus a factor that could potentially influence habitat quality of juvenile flatfishes.

Common sole is a commercially important and widely distributed flatfish of the NorthEast Atlantic region. Parasitic infection of juvenile sole by Prosorhynchus spp. (Digenea, Bucephalidae) metacercariae has recently been reported in the Pertuis Charentais (Laffargue et al., 2004). This area represents an important nursery ground for the common sole stock of the Bay of Biscay, both in terms of density and potential surface area (Le Pape et al., 2003b). However, Le Pape et al. (2003c) also showed that juveniles in this nursery ground had a lower mean size during winter which indicates the poor quality of the area.

Changes in nutritional status and growth of juveniles may reflect their probability of survival in the nursery grounds. Lipid depletion has been identified as a general metabolic response to stress and potentially a response to parasites also (Lemly and Esch, 1984; Lemly, 1997). Total lipid content of a fish is an easy estimation of its physiological condition, but fractionation into individual lipid classes provides a more sensitive measurement of metabolically available lipids and energy allocation (Norton et al., 2001). Lipid class composition has therefore been used to measure the nutritional status of fish at early life stages (Fraser, 1989; Häkanson, 1989; Lochmann et al., 1995; Norton et al., 2001). A nutritional index based on the ratio between quantities of triacyglycerols (TAG: lipid reserves) and free sterols (ST: structural lipids) (TAG / ST) has been used to investigate the nutritional status of sole larvae (Galois et al., 1990; Amara et al., 2000; Amara and Galois, 
2004). In this study, we used both morphometric (Fulton's K) and biochemical condition indices (total lipid content and TAG / ST) to investigate the effect of parasitism on young-ofyear (YOY) sole condition in the Pertuis Charentais. Our aims were to simultaneously analyze changes in infection by digenean metacercariae and the condition of YOY sole from the early settlement period until the onset of winter in the nursery.

\section{Materials and methods}

\subsection{Field sampling}

YOY sole were sampled monthly from May to November 2004 (except October) at one site $\left(46^{\circ} 15^{\prime} 80^{\prime \prime} \mathrm{N}, 1^{\circ} 13^{\prime} 40^{\prime \prime} \mathrm{W}\right)$ located in a mussel pole culture area in the Pertuis Breton, Bay of Biscay (Fig. 1). Fishing was done at low tide during spring tides. From May to July a push-net ( $1 \mathrm{~m}$ wide mounted with a $5 \mathrm{~mm}$ stretched mesh net) was used in the inter-tidal area. From August to November, a standard beam trawl $(2 \mathrm{~m}$ wide and $0.40 \mathrm{~m}$ high, mounted with a $5 \mathrm{~mm}$ stretched mesh net in the codend) was used at around $2 \mathrm{~m}$ depth and at $2.5 \mathrm{knots}$ for 15 min. Sea surface temperature and salinity were recorded several times each day over the whole sampling period, using an automatic recorder situated close to the sampling site. These data were used to calculate mean monthly temperature and salinity (Fig. 1). Average water temperature increased from May $\left(15.3^{\circ} \mathrm{C}\right)$ to a maximum of $21.7^{\circ} \mathrm{C}$ in August, then decreased to $12.1^{\circ} \mathrm{C}$ in November and to $7.3^{\circ} \mathrm{C}$ in winter. Average salinity ranged between 32.5 and 34.5 psu during the sampling period.

The sole were brought to the laboratory alive in an aerated tank with a sandy bottom, in order to reduce capture stress. Fish for lipid analyses were immediately frozen and individually stored at $-80^{\circ} \mathrm{C}$. Other fish, sampled to enlarge the dataset for parasite analysis, were kept at $-20^{\circ} \mathrm{C}$. 


\subsection{Laboratory analyses}

A total sample of 338 fish (Table 1) were individually weighed (to $0.01 \mathrm{~g}$, wet mass $\mathrm{M}_{\mathrm{W}}$ ) and measured (to $1 \mathrm{~mm}$, standard length SL) without correction for shrinkage during preservation. The sole were thawed and dissected to check for digenean metacercariae parasites, which were identified on the basis of morphological features (Matthews, 1973; Maillard, 1974) and then counted.

Lipid analysis was done individually on a subsample of 121 fish (Table 1) after the dissection for parasites was completed. The digestive tracts of fish were first emptied so as to eliminate any lipids other than those from the fish. The extraction procedure followed those of Folch et al. (1957) and Häkanson (1989). Individuals were lyophilized, dry weighed $\left(\mathrm{M}_{\mathrm{D}}\right)$ to the nearest mg, then ground until a thin homogeneous powder was obtained. Approximately $100 \mathrm{mg}$ of this powder was extracted twice with a mixture of chloroform : methanol $(1: 2$ then $2: 1, \mathrm{v} / \mathrm{v})$. A volume of $1 \% \mathrm{NaCl}$ solution was then added and the mixture separated into 2 phases. The lower phase containing the lipids was then collected. An aliquot of this extract was evaporated under a nitrogen flux and redissolved in a volume of chloroform : methanol $(9: 1, v / v)$ calculated to obtain a concentration of approx. $20 \mu \mathrm{g} . \mu \mathrm{l}^{-1}$, the optimal value for measuring total lipids (TL) using a Chromarods SIII - Iatroscan TH-10 system (TLC-FID). 1 $\mu \mathrm{L}$ of each concentrated aliquot was deposited 4 times onto a Chromarod, which was dried and directly read by the Iatroscan without any development. Lipid classes (LC) were separated from a single deposit onto a Chromarod, followed by a development in a mixture of hexane, diethylether and formic acid (85:15:0.05, v/v) for $30 \mathrm{~min}$. Separated LC where then quantified by the Iatroscan using calibration curves obtained from pure lipid standards (Sigma) (Parrish and Ackman, 1985).

Levels of parasitic infection were assessed using classic epidemiological parameters: prevalence $(\mathrm{P} \%)$, the percentage of infected fish in fish sample; and mean abundance $(\mathrm{Ab})$, 
the mean number of parasites per fish, as recommended by Bush et al. (1997). Fulton's condition index was calculated as $\mathrm{K}=\left(\mathrm{M}_{\mathrm{W}} \mathrm{x}\right.$ 100) $/ \mathrm{SL}^{3}$, with $\mathrm{M}_{\mathrm{W}}$ in $\mathrm{g}$ and $\mathrm{SL}$ in $\mathrm{cm}$. Average growth rate was calculated as $\mathrm{AGR}=\left(\right.$ mean $\mathrm{SL}_{\mathrm{t} 2}-$ mean $\left.\mathrm{SL}_{\mathrm{t} 1}\right) /(\mathrm{t} 2-\mathrm{t} 1)$. Percentage $\mathrm{TL}$ in the $\mathrm{M}_{\mathrm{D}}$ and the triacylglycerols to free sterols ratio (TAG / ST) were also calculated as condition indices. The main lipid classes (phospholipids, free sterols, triacylglycerols, free fatty acids, hydrocarbons) were expressed as percentage of $\mathrm{M}_{\mathrm{D}}\left(\% \mathrm{M}_{\mathrm{D}}\right)$ and percentage of TL (\%TL).

\subsection{Data analysis}

Results were considered significant at $\alpha=5 \%$. Values are given as the mean $\pm \mathrm{SE}$ (standard error) for parasite $\mathrm{Ab}$, and mean $\pm \mathrm{SD}$ (standard deviation) for SL, K, TL and TAG / ST. In order to investigate temporal changes in Ab, SL, K, TL and TAG / ST, differences between two consecutive sampled months were analyzed using non-parametric Mann Whitney U tests (MW).

Parasite abundances were $\log$ transformed (log +1 for number of parasites) to normalize the data for the correlation analyses. Relationships of SL and both condition indices (TL and TAG / ST) with parasite abundances were first tested within each sampled month using Pearson correlations. For variables demonstrating significant correlations with SL within a sampled month, residuals of the linear regression between the variable (dependent variable) and SL (independent variable) for this sampled month were used to study the correlations in order to avoid a confounding effect of fish size. Finally the relationships between the lipid indices (TL and TAG / ST) and K, and between parasite abundances and the different condition indices, were analyzed within each sampled month using Pearson correlation. 


\section{Results}

\subsection{Parasitic infection}

YOY sole were infected by two genera of digenean metacercariae: Timoniella spp. (Acanthostomidae) and Prosorhynchus spp. (Bucephalidae). Due to the high abundance of Timoniella spp. metacercariae and their small size, these were only identified at the genus level through the cyst. A dozen individuals were taken as a subsample, removed from their cysts and identified under a microscope. These belonged to the species $T$. praeterita, based on the number of spines on the oral sucker and the anatomy of the digestive caeca (Maillard, 1974). For Prosorhynchus spp., because species identification is often unfeasible from adult morphological features, metacercariae were determined at the genus level only. However, when species identification was possible, a majority of the metacercariae appeared to be $P$. crucibulum.

Timoniella spp. infection started first, with prevalence and mean abundance increasing significantly from May $(\mathrm{P} \%=22 \% ; \mathrm{Ab}=1.9 \pm 1.1 ; \min -\max : 0-57)$ to reach $\mathrm{P} \%=100 \%$ and $\mathrm{Ab}=51.2 \pm 10.4(7-337)$ in August $\left(\mathrm{MW}_{\text {May - June, }} \mathrm{U}_{54,86}=778, \mathrm{P}<0.001 ; \mathrm{MW}_{\mathrm{June}-\mathrm{July}}\right.$, $\left.\mathrm{U}_{86,54}=1530, \mathrm{P}=0.001 ; \mathrm{MW}_{\text {July }- \text { August }}, \mathrm{U}_{54,35}=489, \mathrm{P}<0.001\right)$. Although there was no further significant change in mean abundance of Timoniella spp., the final sample taken in

November had the highest values $(\mathrm{Ab}=54.6 \pm 15.6,0-471)\left(\mathrm{MW}_{\text {August }- \text { September }}, \mathrm{MW}_{\text {September }}\right.$ - November, $\mathrm{P}>0.05$ for all comparisons) (Fig. 2).

Prosorhynchus spp. infection appeared to start later, with prevalence and mean abundance both increasing significantly from June (P\% $=8 \% ; \mathrm{Ab}=0.1 \pm 0.0 ; 0-2)$ to August $(\mathrm{P} \%=100 \% ; \mathrm{Ab}=19.5 \pm 1.7 ; 3-42)\left(\mathrm{MW}_{\text {June }- \text { July }}, \mathrm{U}_{86,54}=675.5, \mathrm{P}<0.001 ; \mathrm{MW}_{\text {July }- \text { August }}\right.$, $\left.\mathrm{U}_{54,35}=155.5, \mathrm{P}<0.001\right)$, mean abundance then stabilized until November which showed the 
highest abundance values $(\mathrm{Ab}=24.8 \pm 3.8,0-87)\left(\mathrm{MW}_{\text {August }- \text { September }}, \mathrm{MW}_{\text {September }- \text { November }}\right.$, $\mathrm{P}>0.05$ for all comparisons).

\subsection{Growth, condition and effect of parasitic infection}

Fulton's K condition index showed weak monthly variations of around 1 on average, with the maximum monthly mean at $1.10 \pm 0.13(0.90-1.48) \mathrm{g} . \mathrm{cm}^{-3}$ in May and the minimum, $0.98 \pm 0.08(0.90-1.10) \mathrm{g} . \mathrm{cm}^{-3}$, in August (Fig. 3). A significant difference between consecutive sampled months only appeared between August and September (MW, $\left.\mathrm{U}_{14,20}=79, \mathrm{P}=0.033\right)$. YOY growth curve, based on mean SL between sampled months, revealed a significant size increase from May $(19.07 \pm 2.97 \mathrm{~mm})$ to November $(85.22 \pm$ $13.53 \mathrm{~mm})\left(\mathrm{MW}_{\text {May - June, }} \mathrm{U}_{15,34}=6, \mathrm{P}<0.001 ; \mathrm{MW}_{\text {June }- \text { July }}, \mathrm{U}_{34,20}=145.5, \mathrm{P}<0.001\right.$; $\mathrm{MW}_{\text {July }- \text { August }}, \mathrm{U}_{20,14}=25.5, \mathrm{P}<0.001 ; \mathrm{MW}_{\text {August }- \text { September }}, \mathrm{U}_{14,20}=6, \mathrm{P}<0.001 ; \mathrm{MW}_{\text {September }-}$ November, $\left.\mathrm{U}_{20,18}=91.5, \mathrm{P}=0.01\right)$ (Fig. 3). Average growth rate (AGR) was highest in late spring: $0.69 \mathrm{~mm} . \mathrm{d}^{-1}$ between May and June. It remained between 0.31 and $0.41 \mathrm{~mm} . \mathrm{d}^{-1}$ during summer and declined from early autumn onwards, to $0.14 \mathrm{~mm} \cdot \mathrm{d}^{-1}$ between September and November.

Total lipids $\left(\% \mathrm{M}_{\mathrm{D}}\right)$ decreased steadily following the early settlement period, from May $(12.62 \pm 1.75 \%)$ to June $(5.93 \pm 1.15 \%)\left(\mathrm{MW}, \mathrm{U}_{15,34}=504, \mathrm{P}<0.001\right)$ (Fig. 4). It then reached a plateau with $5.69 \pm 0.73 \%$ in July and $5.89 \pm 0.79 \%$ in September $\left(\mathrm{MW}_{\text {June }- \text { July, }}\right.$ $\mathrm{MW}_{\text {July - August }}, \mathrm{MW}_{\text {August - September }}, \mathrm{P}>0.05$ for both comparisons), and decreased slightly but significantly to $5.29 \pm 0.40$ in November $\left(M W, \mathrm{U}_{20,18}=266, \mathrm{P}=0.012\right)$.

All lipid classes $\left(\% \mathrm{M}_{\mathrm{D}}\right)$ decreased by approximately the same proportion (about half), from May to June. However, the proportion of TL that they represented (\%TL) remained 
constant during this time. TAG increased in both $\% \mathrm{M}_{\mathrm{D}}$ and $\% \mathrm{TL}$ from August onwards, with maximum values in September and a return to former values in November (Table 2).

TAG / ST did not vary significantly from May $(0.12 \pm 0.12 ; 0.05-0.41)$ to July $(0.08 \pm$ 0.02; 0.06 - 0.12) (MW May - June, $\mathrm{MW}_{\text {June - July }}, \mathrm{P}>0.05$ for both comparisons) (Fig. 4).

However, significant variations were observed between the following months $\left(\mathrm{MW}_{\mathrm{July}}\right.$ - August, $\mathrm{U}_{20,14}=24, \mathrm{P}<0.001 ; \mathrm{MW}_{\text {August }- \text { September }}, \mathrm{U}_{14,20}=24, \mathrm{P}<0.001 ; \mathrm{MW}_{\text {September }- \text { November, }}, \mathrm{U}_{20,18}$ $=342, \mathrm{P}<0.001)$. A steady increase in TAG $/ \mathrm{ST}$ started from August $(0.18 \pm 0.09$; range: $0.07-0.65)$, reaching a maximum in September $(0.57 \pm 0.31 ; 0.16-1.22)$, and followed by a return to the former condition level in November $(0.13 \pm 0.09 ; 0.06-0.37)$.

TAG / ST and SL were positively correlated in May $(\mathrm{n}=15, \mathrm{R}=0.582, \mathrm{P}=0.023)$ and negatively in August $(\mathrm{n}=14, \mathrm{R}=-0.601, \mathrm{P}=0.023)$. Timoniella spp. abundance and SL showed positive correlations in June $(n=34, R=0.385, P=0.025)$ and July $(n=20, R=$ $0.578, \mathrm{P}=0.008)$. Prosorhynchus spp. abundance and SL were negatively correlated in September $(n=20, R=-0.461, P=0.041)$. There were positive correlations between total abundance and SL in July $(\mathrm{n}=20, \mathrm{R}=0.543, \mathrm{P}=0.013)$ and November $(\mathrm{n}=18, \mathrm{R}=0.580, \mathrm{P}$ $=0.012)$.

No significant correlations were detected between K and TL or TAG / ST for any sampled month ( $\mathrm{P}>0.05$ for all correlations). A significant negative correlation was detected between K and Prosorhynchus spp. abundance in November only $(\mathrm{n}=18, \mathrm{R}=-0.552, \mathrm{P}=$ 0.018). No other effects of the parasites on host condition were detected through correlation analyses ( $\mathrm{P}>0.05$ for all other correlations).

\section{Discussion}


In the Bay of Biscay, sole life cycle involves a planktonic larval period lasting around one month which is followed by a complex metamorphosis requiring another ten days on average (Amara et al., 2000). When early settling fish colonize coastal nurseries from April to June, they are presumed to experience high stresses and mortality. Furthermore, stressors encountered by YOY during the first growth period may influence their over-winter survival. However, the phase from settlement to the first winter remains poorly documented in this geographic area.

\subsection{Seasonal infection dynamics}

This paper shows that YOY sole in the Pertuis Breton nursery ground are heavily infected by digenean metacercariae belonging to two genera: Timoniella (Acanthostomidae) and Prosorhynchus (Bucephalidae). For Timoniella spp., the mudflat gastropod Hydrobia spp. is the first intermediate host and the sea bass Dicentrarchus labrax the main definitive host (Maillard, 1974). Based on a subsample of Timoniella spp., it appears that $T$. praeterita could be the species found in YOY sole. These data corroborate Deblock's (1978) inventory of the cercariae of Hydrobia spp. along the French coasts, where only that species was reported in the Pertuis Charentais area. Referring to El-Darsh and Whitfield (1999), our study is therefore the first report of the common sole, Solea solea, as a second intermediate host of $T$. praeterita. The present work also confirms the previous report of infection by Prosorhynchus spp. metacercariae in YOY sole in the Pertuis Breton (Laffargue et al., 2004) and precises that a majority of the metacercariae appeared to be $P$. crucibulum. The first intermediate host for Prosorhynchus spp. is known to be the blue mussel Mytilus edulis and the main definitive host is the conger eel, Conger conger (Matthews, 1973). 
YOY sole infection was characterized by a clear seasonal pattern. Timoniella spp. infection increased from May to reach a plateau from August until November with $100 \%$ prevalence and a mean abundance of 50 parasites per fish. We hypothesize that both water conditions and first intermediate host availability may explain our findings. Even if Hydrobia spp. were not found in the site where fish were sampled, a large population of Hydrobia ulvae is present on the mudflats of the Aiguillon Bay (Degré pers. comm.), close to our sampling site and subject to strong tidal streams. Timoniella spp. cercariae have flagellum-like tail which gives them a high swimming capacity in the water column (Maillard, 1974; El-Darsh and Whitfield, 1999) and thus the ability to infest hosts further away than the cercariae shedding area, especially when strong currents occur. Finally, compared to our results, a lower infection level was found for Platichtys flesus juveniles of the tidal Thames with prevalence around 20\% and mean abundance around 2 (El-Darsh \& Whitfield, 1999). This was assumed to be a result of their migration along the estuary to less saline waters where the first intermediate host, Hydrobia spp., was less abundant or absent. Such up-river migrations are not possible for YOY sole in our study area.

Prosorhynchus spp. infection started one month later (June) than Timoniella spp. infection and 100\% of YOY sole were infected in August, with more than 20 parasites per fish. Thereafter, infection intensity stabilized until November. This result agrees with the timing of infection reported by Coustau et al. (1990): sporocysts release well developed cercariae from mussels in June and July. However, Laffargue et al. (2004) recorded much lower infection levels in YOY sole in the same nursery. Based on 65\% prevalence and mean abundance of around 3 and 8 parasites per fish sampled in August and December respectively, but at a different site in each case, they concluded that there was an autumnal change. Rather than an inter-annual variability in infection, we propose a spatial explanation of the differences with our own study. Prosorhynchus spp. cercariae have low swimming ability, lie 
on the bottom or close to it and mostly infest benthic fishes as second intermediate hosts (Matthews, 1973). Thus, the proximity of the first intermediate host, i.e. a mussel pole culture area, should be the major factor explaining the higher infection in our study, whereas Laffargue et al. (2004) sampled fish with an otter trawl on soft bottoms in stations further away from mussel culture areas.

\subsection{Temporal changes in YOY growth, nutritional status versus parasitic infection}

Following their arrival in the shallower part of the Pertuis Breton nursery, YOY exhibited high growth rates between May and June followed by a decline, and a lower K than indicated by recent reports comparing sole condition in different nurseries (Gilliers et al., 2004). However, this morphological index is known to have low sensitivity and biochemical indices have been recommended to accurately assess condition and growth potential of wild fish juveniles (Weber et al., 2003). Although TAG / ST ratio has been widely used as a nutritional index for early life stages of sole larvae (Galois et al., 1990; Amara et al., 2000; Amara and Galois, 2004), the temporal dynamics of this index in YOY had been little documented.

Metamorphosis has been shown to be critical in terms of effects on growth and condition for a number of flatfishes (Yamashita et al., 2001; Hossain et al., 2003). This is not the case for the common sole however, as metamorphosing sole larvae did not show a halt in growth and were judged to be in good condition as their TAG / ST ratios ranged between 12.5 (Amara et al., 2000; Amara and Galois, 2004). In contrast, our data showed extremely low TAG / ST ratios from May to July, which means that TAG reserves had almost been exhausted during YOY adaptation to the bottom-dwelling habitat. In fact, adaptation to the benthic life style can involve learning, which has been shown for sole (Lagardère et al., 1999). 
This adaptation period may even lead to starvation, as demonstrated by the empty stomachs found in Japanese flounder Paralichthys olivaceus (Tanaka et al., 1996). Settlement in nursery grounds is therefore a crucial transition for sole in terms of their energetic status. A dramatic change in TL was observed in May when it fell from 12 to $6 \%$ of dry body mass. However, initial content conformed with previous reports on post-metamorphic Japanese flounder (Hossain et al., 2003) and sole (Galois, unpubl. data.). The plateau stabilized around 6\%, which is similar to contents measured in autumn for YOY sole in several different nursery grounds on the French Atlantic and Channel coasts (Galois, unpubl. data.). As all lipid classes decreased at the same rate relative to dry mass between May and June, the observed decrease in TL indicates changes in the proximate composition instead of a use of these reserves at this point.

Fish generally ingest food at greater rate during this period of fast growth early in the first year, with extra energy being allocated to storage as lipid reserves. Despite a TAG / ST index at the level of starvation in larvae (Galois et al., 1990), our YOY had full digestive tracts and did not stop growing until autumn. Additionally, condition factor K, TL, and TAG / ST were not significantly related, whereas a positive correlation would be expected when lipid reserves are used as the main supply of energy (Lemly and Esch, 1984; Fraser, 1989; Pangle and Sutton, 2005). Lipid storage is not the only way for fish to store energy: a dramatic increase in glycogen content was observed during compensatory growth in young roach Rutilus rutilus (Mendez and Wieser, 1993). Hence, although energy allocation in YOY sole remains poorly understood, our findings could indicate suboptimal feeding conditions and/or a preferential use of glycogen as an energetic reserve offering more rapid storage and mobilization early during the first summer, when growth appears to be the priority.

TAG / ST peaked in September, when the highest variability also appeared $(0.57 \pm$ 0.31). This indicates that at least some of the YOY stored energy supplies in the form of TAG 
during late summer. Although these levels were higher than in August they were below those found in other nursery grounds in the French Atlantic and Channel coastal areas but corresponded to values already measured in autumn 2003 in the Pertuis Breton nursery area (Galois, unpubl. data.). Lipid storage is generally observed prior to winter and allows fish to survive periods of starvation, which are more frequent in winter. The steep decrease in TAG / ST in November could indicate a period of starvation between September and November. It could also mean that fish with higher TAG / ST ratios could have moved to deeper waters, which is the generally observed migration pattern (Dorel et al., 1991; van der Veer et al., 2001).

Parasites are known to be major stressors for aquatic organisms (Lemly, 1997). Metacercariae feed directly on host tissue to develop and induce host immune responses (Jones, 2001). Thus parasitism involves an energetic cost due to both parasite nutrition and host reaction. Studies on cases of heavy infection have demonstrated negative effects of metacercariae on fish host growth and stored lipid supplies, which impact over-winter survival (Lemly and Esch, 1984; Coleman and Travis, 1998; Johnson and Dick, 2001; Collyer and Stockwell, 2004). In contrast, other studies reported a lack of effects of metacercariae on fish condition and survival (Ballabeni, 1994; Ondrackova et al., 2004). In the present study, we only detected a negative relationship between Prosorhynchus spp. abundance and the condition factor $\mathrm{K}$ in November, which differs from previously published results (Laffargue et al., 2004). However, we did not find any relationship between parasite abundance and the other more sensitive biochemical condition indices (TL and TAG/ST). From settlement to early fall, YOY sole were increasingly infected by both parasites, Prosorhynchus spp. and Timoniella spp. and although they had a poor nutritional status, they appeared to have had the capacity to compensate for such an infection. In November when the temperature lowered, the 
decreased condition linked to parasitism may corroborate the "winter stress syndrome" (Lemly,1997).

In conclusion, this study clearly demonstrates that 1) settlement in the nursery is a critical transition period for sole in terms of nutritional status and 2), YOY infection results from local accumulation of digenean metacercariae. In this shellfish-dominated bay, the presence of the first intermediate hosts in the same habitat favors YOY sole infection by Timoniella spp. and Prosorhynchus spp. metacercariae. However, we did not detect any negative effects of these parasites until November. We described seasonal changes in energy storage from summer to winter. During the first summer of growth, we assume that YOY preferentially use glycogen to allocate energy between growth and storage, only resuming their use of lipid reserves in late summer. In autumn, YOY sole that remained in this shallow part of the nursery exhibit poor nutritional status, heavy infection levels and an effect of parasites on their condition which may decrease their over-winter survival. This area of the Pertuis Breton thus appears to be of very low quality for sole.

\section{Acknowledgments}

We are very grateful to J. Grizon, G. Pinaudeau and M. Paillet for their valuable help with field sampling and laboratory analyses. A PhD grant to E.D.H. Durieux was funded by IFREMER and the Conseil Régional de Poitou-Charentes. Financial support for the research project was provided by the Contrat Plan Etat Région Poitou-Charentes and by IFREMER Défi Golfe de Gascogne. We would like to thank H. Boudry for English improvement of the manuscript. 


\section{References}

Amara, R., Galois, R., 2004. Nutritional condition of metamorphosing sole: spatial and temporal analyses. J. Fish Biol. 64, 72-88.

Amara, R., Lagardère, F., Désaunay, Y., Marchand, J., 2000. Metamorphosis and estuarine colonisation in the common sole, Solea solea (L.): implications for recruitment regulation. Oceanol. Acta 23, 469-484.

Anderson, R., May, R., 1978. Regulation and stability of host-parasite population interactions.

I. Regulatory processes. J. Anim. Ecol. 47, 219-247.

Ballabeni, P., 1994. Experimental differences in mortality patterns between European minnows, Phoxinus phoxinus, infected with sympatric or allopatric trematodes, Diplostomum phoxini. J. Fish Biol. 45, 257-567.

Bush, A., Lafferty, K.D., Lotz, J., Shostak, A., 1997. Parasitology meets ecology on its own terms: Margolis et al. revisited. J. Parasitol. 83, 575-583.

Coleman, F., Travis, J., 1998. Phenology of recruitment infection patterns of Ascocotyle pachycyctis, a digenean parasite in the sheephead minnow, Cyprinodon variegatus. Environ. Biol. Fish. 51, 87-96.

Collyer, M., Stockwell, C., 2004. Experimental evidence for costs of parasitism for a threatened species, White Sands pupfish (Cyprinodon tularosa). J. Anim. Ecol. 73, 821-830. Combes, C., 2001. Parasitism. The ecology and evolution of intimate interactions. Chicago Univ. Press, Chicago.

Coustau, C., Combes, C., Maillard, C., Renaud, F., Delay, B., 1990. Prosorhynchus squamatus (Trematoda) parasitosis in the Mytilus edulis-Mytilus galloprovincialis complex: specificity and host-parasite relationship. In: Perkins, F., Cheng, T. (Eds), Pathology in Marine Science. Elsevier, Amsterdam, pp. 291-298. 
Cribb, T.H., Bray, R.A., Littlewood, D.T.J., 2001. The nature and evolution of the association among digeneans, molluscs and fishes. Int. J. Parasitol. 31, 997-1011.

Deblock, S., 1978. Distribution géographique des cercaires parasites des Mollusques du genre Hydrobia Hartman des côtes de France. Ann. Parasitol. Hum. Comp. 53, 577-593.

Dorel, D., Koutsikopoulos, C., Désaunay, Y., Marchand, J., 1991. Seasonal distribution of young sole (Solea solea (L.)) in the nursery ground of the Bay of Vilaine (Northern Bay of Biscay). Neth. J. Sea Res. 27, 297-306.

El-Darsh, H.E.M., Whitfield, P.J., 1999. Digenean metacercariae (Timoniella spp., Labratrema minimus and Cryptocotyle concava) from flounder, Platichthys flesus, in the tidal Thames. J. Helminthol. 73, 103-113.

Folch, J., Lees, M., Sloane Stanley, G., 1957. A simple method for the isolation and purification of total lipids from animal tissues. J. Biol. Chem. 226, 497-509.

Fraser, A., 1989. Triacylglycerol content as a condition index for fish, bivalve, crustacean larvae. Can. J. Fish. Aquat. Sci. 46, 1868-1873.

Galois, R., Lagardère, F., Richard, P., 1990. Changes in biochemical composition and otolith microstructure of larval common soleas, Solea solea (L.) under experimental starvation. La mer 28, 273-285.

Gibson, R.N., 1994. Impact of habitat quality and quantity on the recruitment of juvenile flatfishes. Neth. J. Sea Res. 32, 191-206.

Gilliers, C., Amara, R., Bergeron, J.-P., Le Pape, O., 2004. Comparison of growth and condition indices of juvenile flatfish in different coastal nursery grounds. Environ. Biol. Fish. 71, 189-198.

Häkanson, J., 1989. Analysis of lipid components for determining the condition of anchovy larvae, Engraulis mordax. Mar. Biol. 102, 143-151. 
Hossain, M.A.R., Tagawa, M., Masuda, R., Tanaka, M., 2003. Changes in growth performance and proximate composition in Japanese flounder during metamorphosis. J. Fish Biol. 63, 1283-1294.

Johnson, M., Dick, T., 2001. Parasite effects on the survival, growth, and reproductive potential of yellow perch (Perca flavescens Mitchill) in canadian Shield lakes. Can. J. Zool. 79, 1980-1992.

Jones, S.R.M., 2001. The occurence and mechanisms of innate immunity against parasites in fish. Dev. Comp. Immunol. 25, 841-852.

Laffargue, P., Baudoin, G., Sasal, P., Arnaud, C., Begout Anras, M.L., Lagardère, F., 2004. Parasitic infection of sole Solea solea by Prosorhynchus spp. metacercariae (Digenea, Bucephalidae) in Atlantic nurseries under mussel cultivation influence. Dis. Aquat. Org. 58, 179-184.

Lagardère, F., Amara, R., Joassard, L., 1999. Vertical distribution and feeding activity of metamorphosing sole, Solea solea, before immigration to the Bay of Vilaine nursery (northern Bay of Biscay, France). Environ. Biol. Fish. 56, 213-228.

Le Pape, O., Chauvet, F., Désaunay, Y., Guérault, D., 2003a. Relationship between interannual variations of the river plume and the extent of nursery grounds for the common sole (Solea solea, L.) in Vilaine Bay. Effects on recruitment variability. J. Sea Res. 50, 177185.

Le Pape, O., Chauvet, F., Mahevas, S., Lazure, P., Guérault, D., Désaunay, Y., 2003b. Quantitative description of habitat suitability for the juvenile common sole (Solea solea, L.) in the Bay of Biscay (France) and the contribution of different habitats to the adult population. J. Sea Res. 50, 139-149. 
Le Pape, O., Holley, J., Guérault, D., Désaunay, Y., 2003c. Quality of coastal and estuarine essential fish habitats: estimations based on the size of juvenile common sole (Solea solea L.). Est. Coast. Shelf Sci. 58, 793-803.

Lemly, A., 1997. Role of season in aquatic hazard assessment. Environ. Monit. Assess. 45, $89-98$.

Lemly, A., Esch, G., 1984. Effects of the trematode Uvulifer amblopilis on juvenile bluegill sunfish, Lepomis macrochirus: ecological implications. J. Parasitol. 70, 475-492.

Lochmann, S., Maillet, G., Frank, K., Taggart, C., 1995. Lipid class composition as a measure of nutritional condition in individual larval Atlantic cod (Gadus morhua). Can. J. Fish. Aquat. Sci. 52, 1294-1306.

Maillard, C., 1974. Cycle évolutif de Timoniella praeteritum (Loss 1901) (Trematoda, Acanthostomidae) parasite de Morone labrax (teleostei, Serranidae). Bull. Soc. Zool. Fr. 99, 245-257.

Matthews, R.A., 1973. The life-cycle of Prosorhynchus crucibulum (Rudolphi, 1819 Odhner, 1905, and a comparison of its cercaria with that of Prosorhynchus squamatus Odhner, 1905. Parasitology 66, 133-164.

May, R., Anderson, R., 1978. Regulation and stability of host-parasite population interactions: II. Destabilizing processes. J. Anim. Ecol. 47, 249-267.

Mendez, G., Wieser, W., 1993. Metabolic responses to food deprivation and refeeding in juveniles of Rutilus rutilus (Teleostei: Cyprinidae). Environ. Biol. Fish. 36, 73-81.

Nash, R.D.M., Geffen, A.J., 2000. The influence of nursery ground processes in the determination of year-class strength in juvenile plaice Pleuronectes platessa L. in Port Erin Bay, Irish Sea. J. Sea Res. 44, 101-110. 
Norton, E.C., MacFarlane, R.B., Mohr, M.S., 2001. Lipid class dynamics during development in early life stages of shortbelly rockfish and their application to condition assessment. J. Fish Biol. 58, 1010-1024.

Ondrackova, M., Reichard, M., Jurajda, P., Gelnar, M., 2004. Seasonal dynamics of Posthodiplostomum cuticola (Digenea, Diplostomatidae) metacercariae and parasite-enhanced growth of juvenile host fish. Parasitol. Res. 93, 131-136.

Pangle, K.L., Sutton, T.M., 2005. Temporal changes in the relationship between condition indices and proximate composition of juvenile Coregonus artedi. J. Fish Biol. 66, 1060-1072. Parrish, C.C., Ackman, R., 1985. Calibration of Iatroscan chromarod system for marine lipid classes. Lipids 20, 521-530.

Tanaka, M., Kawai, S., Seikai, T., Burke, J., 1996. Development of the digestive organ system in Japanese flounder in relation to metamorphosis and settlement. Mar. Freshw. Behav.

Physiol. 28, 19-31.

van der Veer, H.W., Dapper, R., Witte, J.I., 2001. The nursery function of the intertidal areas in the western Wadden Sea for 0-group sole Solea solea (L.). J. Sea Res. 45, 271-279.

van der Veer, H.W., R, B., Rijnsdorp, A.D., 1994. Impact of juvenile growth on recruitment in flatfish. Neth. J. Sea Res. 32, 153-173.

Weber, L.P., Higgins, P.S., Carlson, R.I., Janz, D.M., 2003. Development and validation of methods for measuring multiple biochemical indices of condition in juvenile fishes. J. Fish Biol. 63, 637-658.

Yamashita, Y., Tanaka, M., Miller, J.M., 2001. Ecophysiology of juvenile flatfish in nursery grounds. J. Sea Res. 45, 205-218. 


\section{Table 1}

Date of capture, sample size $(\mathrm{N})$ and standard length (SL) range (mm) for the total sample (individuals on which parasite analysis was carried out) and the subsample (individuals on which lipid composition analysis was carried out after parasite analysis).

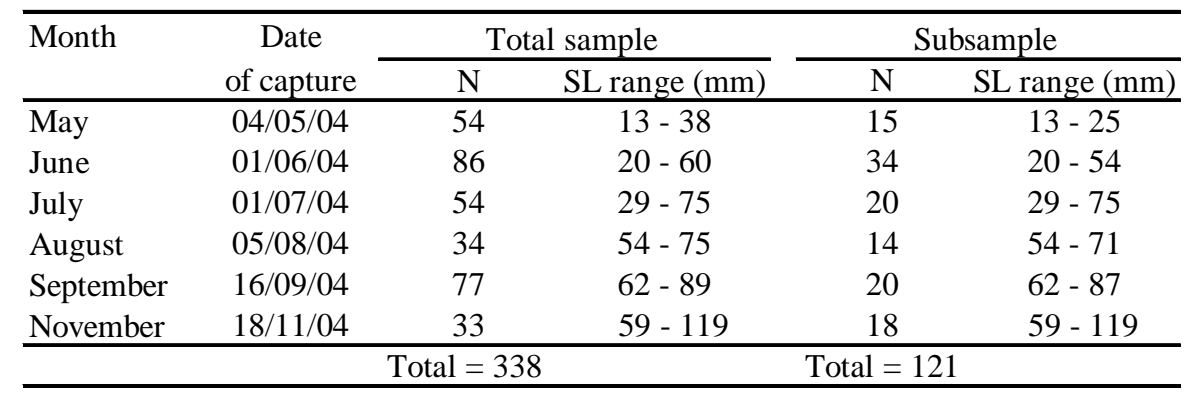




\section{Table 2}

Temporal changes in the main lipid classes (PL: phospholipids; ST: free sterols; TAG:

triacylglycerols; FFA: free fatty acids; HC: hydrocarbons) of total lipids from YOY sole,

Solea solea, as percentages of dry mass $\left(\% \mathrm{M}_{\mathrm{D}}\right)$ and of total lipids $(\% \mathrm{TL})( \pm$ standard deviation).

\begin{tabular}{llccccc}
\hline Month & PL & ST & TAG & FFA & HC \\
\hline & May & $8.25 \pm 1.32$ & $1.55 \pm 0.33$ & $0.20 \pm 0.18$ & $0.40 \pm 0.10$ & $0.16 \pm 0.04$ \\
& June & $4.66 \pm 0.93$ & $0.83 \pm 0.14$ & $0.10 \pm 0.13$ & $0.21 \pm 0.04$ & $0.09 \pm 0.04$ \\
$\% \mathrm{M}_{\mathrm{D}}$ & July & $4.49 \pm 0.58$ & $0.82 \pm 0.12$ & $0.06 \pm 0.02$ & $0.21 \pm 0.04$ & $0.08 \pm 0.02$ \\
& August & $4.74 \pm 0.58$ & $0.82 \pm 0.14$ & $0.16 \pm 0.09$ & $0.21 \pm 0.04$ & $0.09 \pm 0.03$ \\
& September & $4.45 \pm 0.72$ & $0.73 \pm 0.11$ & $0.40 \pm 0.21$ & $0.18 \pm 0.03$ & $0.08 \pm 0.02$ \\
November & $4.23 \pm 0.32$ & $0.69 \pm 0.06$ & $0.09 \pm 0.06$ & $0.17 \pm 0.02$ & $0.07 \pm 0.02$ \\
\hline & May & $77.81 \pm 2.84$ & $14.62 \pm 2.17$ & $1.72 \pm 1.37$ & $3.71 \pm 0.69$ & $1.50 \pm 0.34$ \\
& June & $78.59 \pm 2.73$ & $14.17 \pm 1.58$ & $1.58 \pm 1.75$ & $3.55 \pm 0.49$ & $1.47 \pm 0.52$ \\
\% TL & July & $78.97 \pm 1.70$ & $14.33 \pm 1.17$ & $1.08 \pm 0.27$ & $3.62 \pm 0.44$ & $1.34 \pm 0.23$ \\
& August & $78.46 \pm 2.15$ & $13.55 \pm 1.23$ & $2.45 \pm 1.25$ & $3.41 \pm 0.48$ & $1.48 \pm 0.30$ \\
& September & $75.42 \pm 4.11$ & $12.42 \pm 0.99$ & $7.03 \pm 3.74$ & $3.14 \pm 0.36$ & $1.34 \pm 0.31$ \\
& November & $80.09 \pm 1.40$ & $13.03 \pm 0.93$ & $1.60 \pm 1.04$ & $3.29 \pm 0.37$ & $1.35 \pm 0.34$ \\
\hline
\end{tabular}


Fig. 1. The Pertuis Charentais area (Bay of Biscay, France, Atlantic Ocean) with the location of the sampling site (black star) for YOY sole, Solea solea, and seasonal variation of mean sea surface temperature $\left({ }^{\circ} \mathrm{C}\right)$ (solid line) and salinity (psu) (dotted line) during the sampling year (2004)

Fig. 2. Temporal changes in prevalence (dotted line) and mean abundance (solid line) of Timoniella spp. (black squares) and Prosorhynchus spp. (white triangles) in YOY sole, Solea solea, from the Pertuis Breton $(\mathrm{N}=338)$. Error bars are standard errors

Fig. 3. Temporal changes of mean standard length (SL) (mm) (white circles) and mean Fulton's K condition factor $\left(\mathrm{g} . \mathrm{cm}^{-3}\right)$ (black diamonds) of YOY sole, Solea solea, from the Pertuis Breton $(\mathrm{N}=121)$. Error bars are standard deviations

Fig. 4. Temporal changes in total lipids (TL) (\% of dry mass $\mathrm{M}_{\mathrm{D}}$ ) (a) and triacylglycerols / sterols ratio (TAG / ST) (b) in YOY sole , Solea solea, from the Pertuis Breton $(\mathrm{N}=121)$. Error bars are standard deviations 

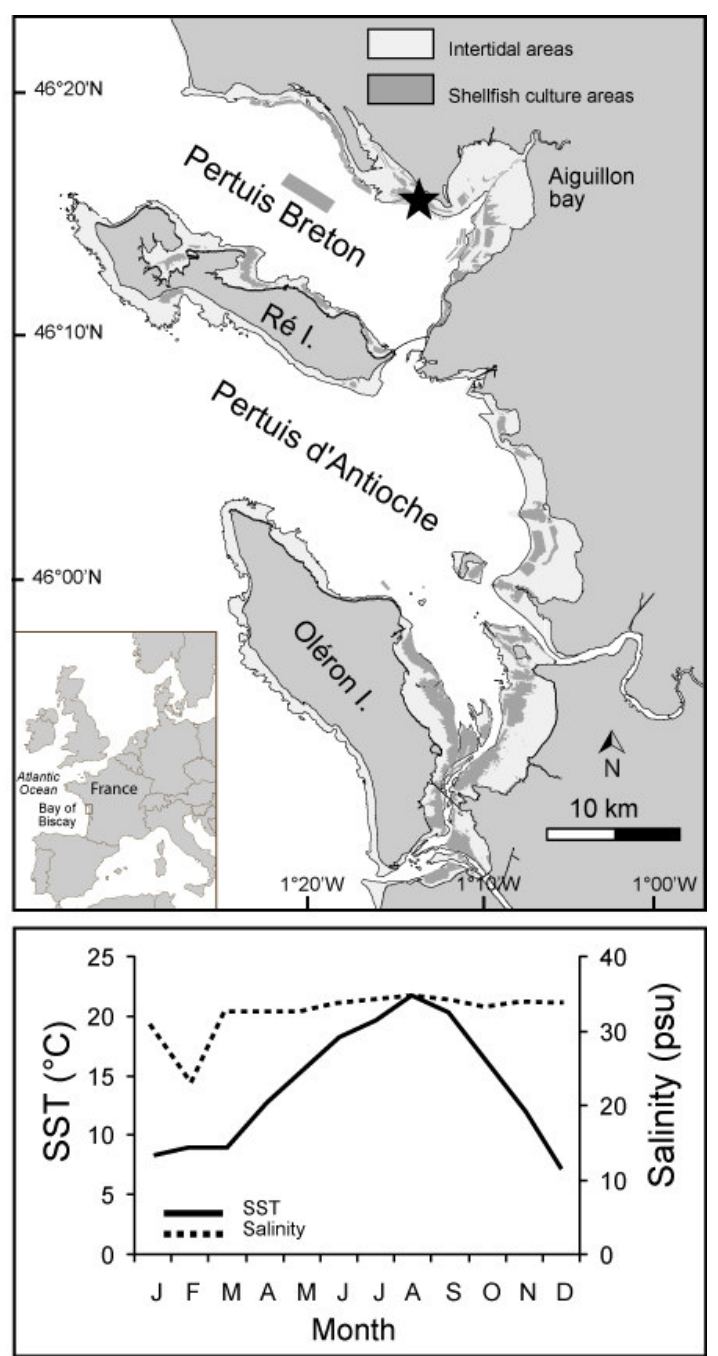

Fig. 1. 


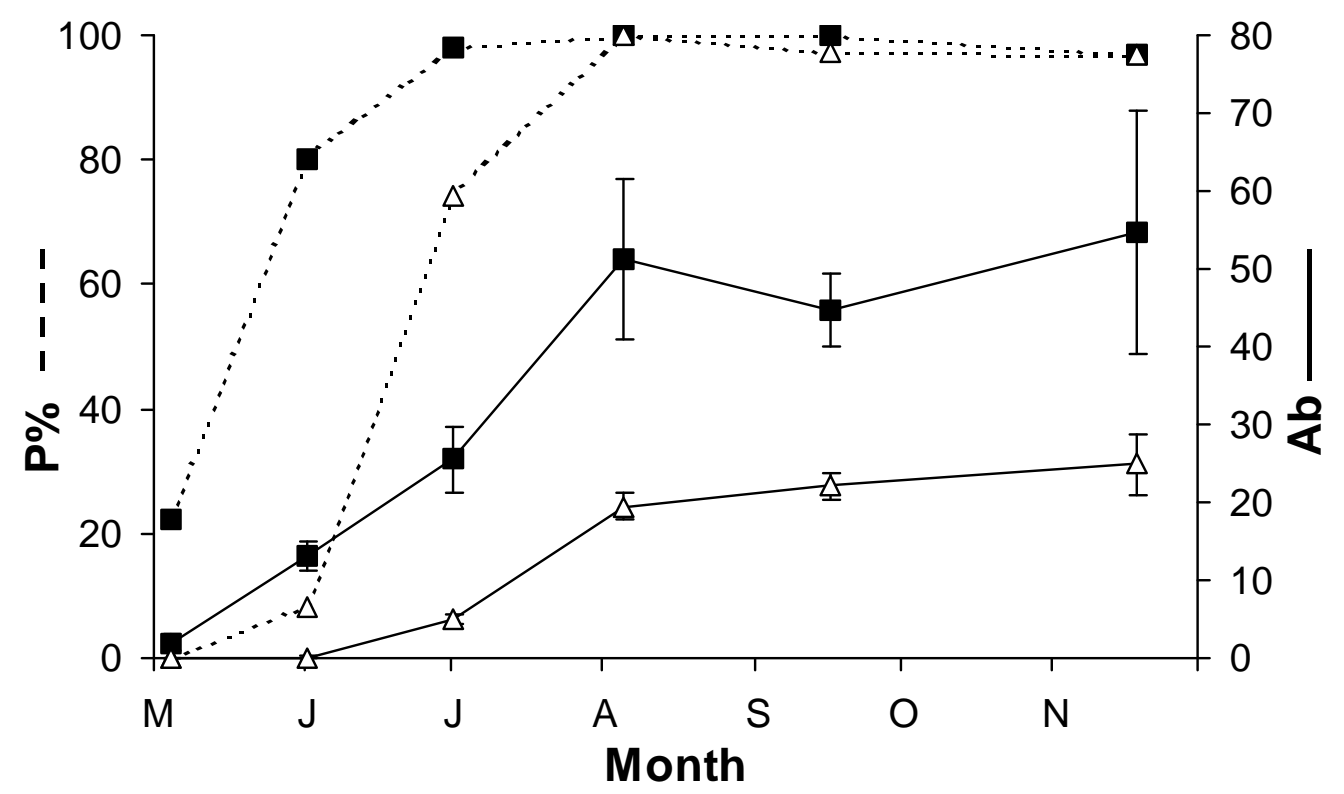

Fig. 2. 


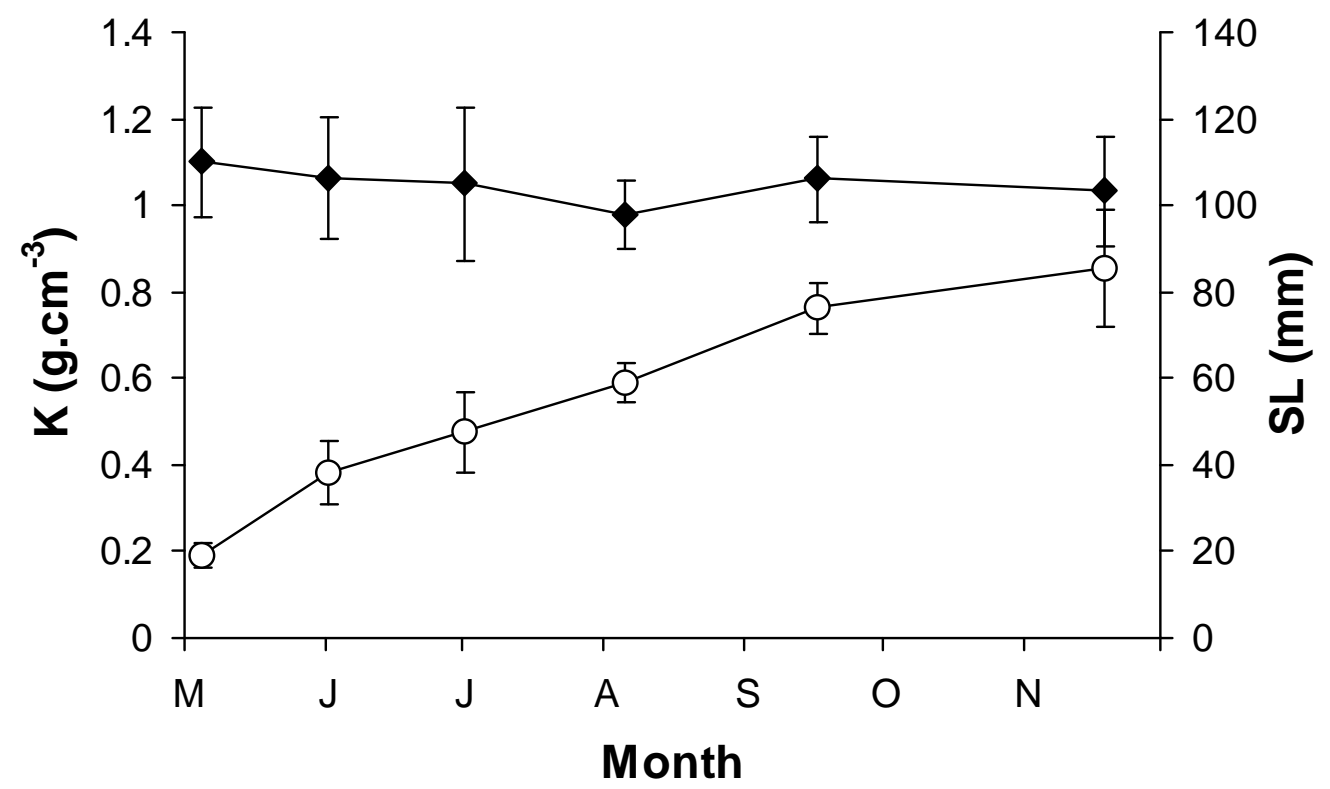

Fig. 3. 

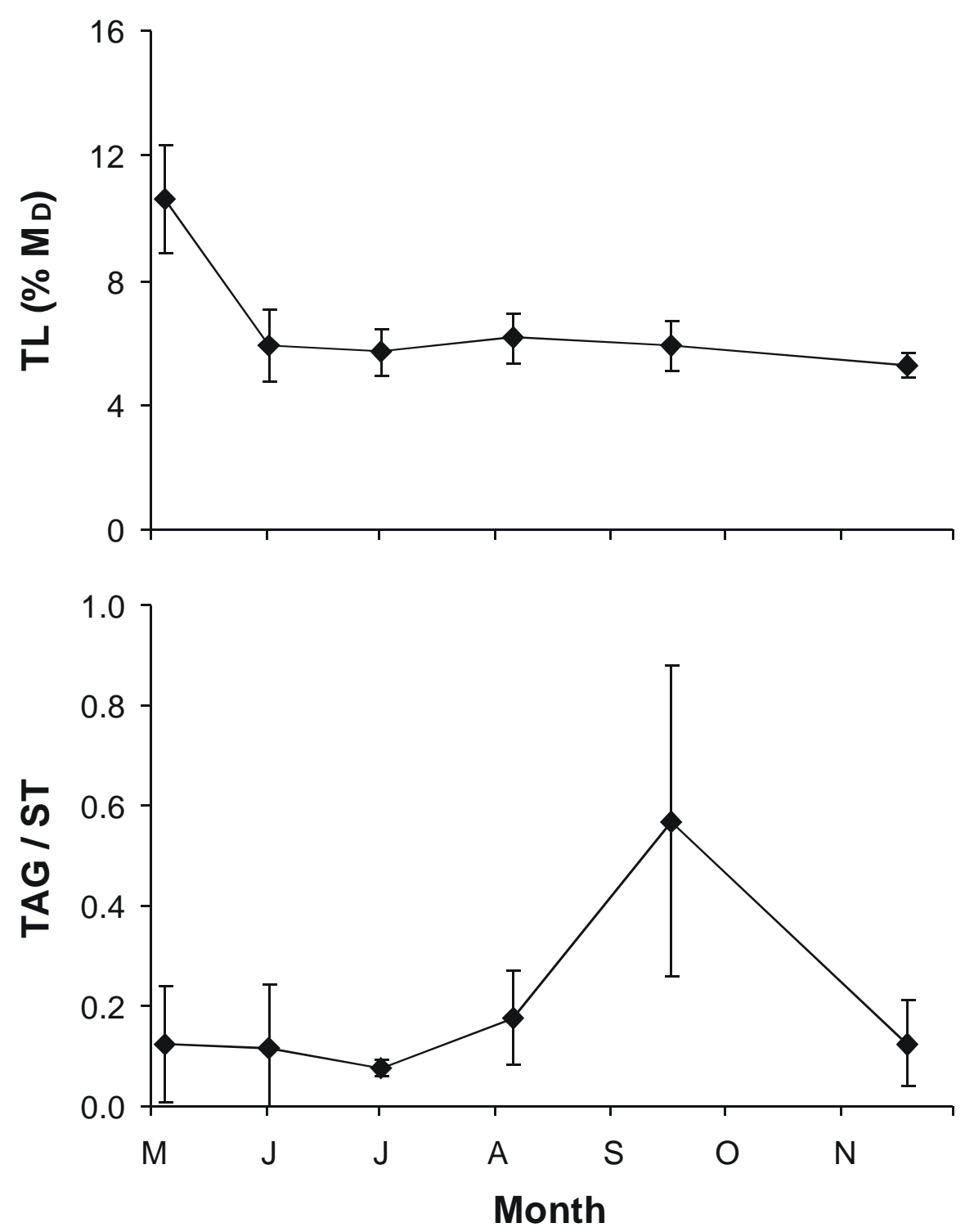

Fig. 4. 